\title{
Physical activity and health-related quality of life in chronic low back pain patients: a cross-sectional study
}

\author{
Andrea Schaller $^{1 *}$, Lea Dejonghe ${ }^{1}$, Burkhard Haastert $^{2}$ and Ingo Froboese ${ }^{1}$
}

\begin{abstract}
Background: The aim of the present study was to identify the relationship of physical activity (PA) and Health-Related Quality of Life (HRQoL) in patients suffering from low back pain (LBP).

Methods: The present evaluation was conducted as a cross-sectional study based on baseline data of an randomized controlled trial on the effectiveness of an intervention promoting PA. Patients answered a questionnaire on domain specific PA (GPAQ) and HRQoL (EQ-5D-5 L). Furthermore, sociodemographic and indication-specific variables as well as work-related aspects were assessed. Associations of PA and HRQoL were estimated by means of regression analysis: one regression model only included domain specific PA (model 1) and a second regression model additionally included further variables (model 2).
\end{abstract}

Results: 412 patients completed the questionnaire. Model 1 showed opposed effects of workplace and leisure time PA: while workplace PA showed a negative association $(\beta=-0.064 ; p=0.04)$, a positive association of leisure time PA could be proved $(\beta=0.068 ; p=0.01$ ). Model 2 showed that only the variables "current work ability" ( $\beta=-0.030 ; p<0.01)$ and "intensity of pain" $(\beta=0.104 ; p<0.01)$ significantly contributed to explain the variance in HRQoL (model 2).

Conclusions: The present results indicate the necessity of a differentiation of workplace and leisure time PA in the context of assessing health-enhancing effects of PA in LBP patients. In the context of HRQoL it must be assumed that the relevance of PA might be overestimated. Further research should be performed on predictors of HRQoL and thereby particular attention should be paid on the patients' work-related and indication-specific aspects.

Keywords: Physical activity, Chronic low back pain, Health Related Quality of Life, Rehabilitation

\section{Background}

Physical activity (PA) is widely recognized as an important health-related lifestyle factor. The social, psychosocial and also biological health benefits of PA and exercise are well established and there is clear scientific evidence that moderate PA on a regular basis can reduce the risk of the morbidity of preventable non-communicable diseases (NCDs) $[1,2]$. Overall, lack of PA is mentioned as one of the four behavioral risk factors causing NCDs [3,4]. Also the benefit of regular PA in primary and secondary prevention as

\footnotetext{
* Correspondence: a.schaller@dshs-koeln.de

'Institute of Health Promotion and Clinical Movement Science, German Sport University Cologne, Am Sportpark Muengersdorf 6, 50933 Cologne, Germany Full list of author information is available at the end of the article
}

well as in the rehabilitative treatment of several NCDs is scientifically recognized. Observational and interventional studies proved positive effects of PA for diabetes, hypertension, cancer (esp. breast and colon cancer), osteoporosis, cardiovascular disease, obesity and depression $[5,6]$. World Health Organisation (WHO) guidelines addressing healthy adults and adults with NCDs not related to mobility (e.g., such as hypertension or diabetes) recommend at least 150 minutes of moderate-intensity or 75 minutes of vigorous-intensity aerobic PA throughout the week or an equivalent combination of moderate- and vigorous-intensity activity. Independent of intensity, aerobic activity should be performed in bouts of at least 10 minutes duration [7].

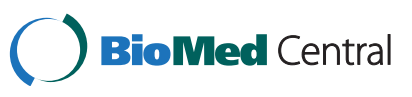

(c) 2015 Schaller et al.; licensee BioMed Central. This is an Open Access article distributed under the terms of the Creative Commons Attribution License (http://creativecommons.org/licenses/by/4.0), which permits unrestricted use, distribution, and reproduction in any medium, provided the original work is properly credited. The Creative Commons Public Domain Dedication waiver (http://creativecommons.org/publicdomain/zero/1.0/) applies to the data made available in this article, unless otherwise stated. 
These recommendations relate not only to sports, but also to other leisure activities, work and transport activity [7].

Besides morbidity and mortality, patient-oriented outcomes, such as Health-Related Quality of Life (HRQoL), are of utmost importance in rehabilitation and health services research [8]. While quality of life is defined as a broad concept that incorporates all aspects of an individual's existence, HRQoL is considered to be a subset relating only to the health domain of that existence [9]. For developing patient-oriented treatments it is of utmost importance to understand what influences HRQoL. In this context, the associations of lifestyle factors, such as PA behavior, and HRQoL need to be examined to identify target-group specific approaches to promote HRQoL. Concerning the influence of PA on HRQoL, a systematic review showed a positive association in general population [10] and PA is considered as a lifestyle factor having the potential to increase the quality of life [2]. Compared to healthy persons, a lower HRQoL of patients suffering from NCDs could be demonstrated $[11,12]$ but it also could be shown that physically active persons in this population group tend to improved HRQL [13].

Low back pain (LBP) is not only one of the leading causes of pain and disability but also of a costly burden on the healthcare budget as LBP leads to a frequent demand for medical services $[14,15]$. The lifetime prevalence of LBP is estimated $74 \%$ to $85 \%$ and almost $20 \%$ of the population is suffering from either severe or disabling back pain $[16,17]$. Despite the relevance of LBP patients in health services research, the associations of lifestyle factors on HRQoL in this patient group are rarely examined. PA is ascribed a potential role in the prevention of chronic LBP and therefore can be considered as an essential lifestyle in LBP patients [18-20]. Furthermore, the relevance of PA in the context of LBP is ascribed to its potential to reduce potential risk factors of LBP, e.g., obesity [21].

A better understanding of how PA is associated to HRQoL contributes to a comprehensive understanding of HRQoL and also to the development of target-group specific approaches to increase HRQoL in LBP patients. Therefore, the present paper aims to 1) explore the association between domain specific PA and HRQoL and 2) identify variables associated with HRQoL in LBP patients.

\section{Methods}

\section{Subjects and study design}

Data were collected as part of a randomized controlled trial (RCT), evaluating the effectiveness of an intervention on physical activity promotion (German Clinical Trials Register (DRKS)-ID: DRKS00004878). Ethical approval was granted by German Sport University Ethics Committee (reference number: 56/12). The study was conducted in compliance with the Helsinki Declaration. The present evaluation was conducted as a cross-sectional study based on baseline data of the RCT [22]. Eligible patients were 18 to 65 years of age and starting an inpatient medical rehabilitation treatment because of LBP. Patients were invited to participate in the study during an information seminar on PA. All patients receiving inpatient rehabilitation because of LBP were included in the study. Exclusion criteria were cognitive disorders, lack of understanding the German language, any kind of surgery within the last three months, posttraumatic conditions (e.g. LBP after an accident) a current state pension claim and refusal of participating in the RCT. At the time of the data collection, patients did not know whether they had been randomized into the intervention or control group. In the period of recruitment 931 LBP patients were eligible to participate in the study. All patients participating signed written informed consent to participate in the RCT. Patient recruitment was conducted monocentric in an inpatient rehabilitation center of the German Statutory Pension Insurance Rhineland. Data were collected consecutively from April 2013 to April 2014.

\section{Measurements}

Patients answered a questionnaire on PA, HRQoL and sociodemographic aspects. HRQoL was measured using the EQ-5D, a standardized, preference based measure of health status. Preference-based approaches are often used in cost-effectiveness analyses and incorporate values or utilities for health outcomes [23]. The EQ-5D is designed for self-completion and assesses five dimensions of HRQoL: mobility, self-care, daily activities, pain and discomfort, anxiety or depression [24]. In the present study, the new version of the questionnaire, EQ-5D-5 L, was applied [25]. EQ-5D-5 L provides five levels for answering each dimension: no problems, slight problems, moderate problems, severe problems and extreme problems. Descriptive answers were converted into a single summary index by applying a formula that essentially attaches weights to each of the levels in each dimension (German version) and using the crosswalk value set for the EQ-5D$5 \mathrm{~L}$. The crosswalk is based on a response mapping approach that estimates the relationship between responses to the EQ-5D-3 L ('3 L') and EQ-5D-5 L ('5 L') descriptive systems, and subsequently established a link to the established $3 \mathrm{~L}$ value sets [25]. Index value of health status range from ' 1 ' (perfect health) to ' 0 ' (death). States perceived to be worse than death have a negative summary score index.

PA was operationalised by Global Physical Activity Questionnaire (GPAQ) [26,27]. The GPAQ collects information on PA during a typical week within three domains (or settings) as well as sedentary behavior. The domains referred to are PA at work (paid and unpaid), transport activity (travel to and from places, for example by walking and cycling) and recreational activities (e.g., sports, fitness and recreational activities (leisure)). 
The GPAQ comprises of 16 questions and, for each domain, PA is assessed if it was continuously performed for at least ten minutes. Work and leisure time physical activity are specifically measured with respect to their intensity ${ }^{\mathrm{a}}$. Therefore, vigorous intensity is described as "activities that cause large increases in breathing or heart rate". The GPAQ is scored by multiplying the minutes per week for each domain by their associated MET to create MET-min scores per week. In the comparison with the International Physical Activity Questionnaire (IPAQ), a previously validated and accepted PA questionnaire, the GPAQ showed a moderate to strong positive relationship (concurrent validity: Spearman's rho $0.45-0.65$ ). Pedometer studies showed fair pooled criterion validity for total PA $(r=0.31)$ and reliability was of moderate to substantial strength (kappa from 0.67 to 0.73; Spearman's rho from 0.67 to 0.81 ) [27]. A further study evaluating criterion validity in comparison with accelerometer showed that the minutes of moderate and vigorous PA were correlated with the accelerometer measurements of moderate $(r=0.28)$ and vigorous $(r=0.48) \mathrm{PA}$. GPAQ data were checked for possible data entry errors by using the provided WHO CleanRecode program [28]. Additionally, plausibility check was performed. Based on interdisciplinary discussions, possible maximum for work related PA was defined $2400 \mathrm{~min} /$ week (equates to eight hours a day five days a week). For transport leisure time PA, maximum of $3360 \mathrm{~min} /$ week (equates to eight hours a day seven days a week) was considered as maximum. Data higher than the defined maximum were set to the defined maximum.

Sociodemographic variables collected were age, gender, partnership, level of education and body mass index (BMI). BMI data were classified: BMI from $20-24.9$ was defined "normal weight", BMI from 25 - 29.9 "overweight" and $\geq 30$ "obese" [29]. Additionally, work-related and indication-specific variables were collected. Workrelated variables refer to current employment status (employed/unemployed), sick certificate before rehabilitation ( $<6$ weeks $>6$ weeks), current work ability compared to highest work ability ever (Assume that your work ability at its best has a value of 10 points. How many points would you give your current work ability? (0 means that you currently cannot work at all)) as an item from work ability index [30]. Indication-specific variables were duration of LBP ( $\leq 12$ months/> 12 months) and intensity of pain. Intensity of pain during the last four weeks" was measured via a question from the SF-36 questionnaire ("How much bodily pain have you had during the past 4 weeks?"; answering on a scale from 1 (none) to 6 (very severe)) [31].

\section{Statistical analysis Coding of variables}

Physical inactivity was defined as $0 \mathrm{~min}$ PA/week, equivalent to not performing PA continuously for at least ten minutes in the life domain referred to in the GPAQ. For the regression models, the PA variables were classified: Transport PA was dichotomized ("no transport PA (0 min/week)"/“transport PA"), workplace PA and leisure time PA were divided into three classes each. Cut-off at workplace PA was set at "no workplace PA (0 min/week)"। "moderate or vigorous workplace PA"/"moderate and vigorous workplace PA". Classification of leisure time PA was conducted referring to WHO-recommendations ("no leisure time PA (0 MET-min/week)"/“<600 MET-min"/“ $\geq 600$ MET-min").

\section{Descriptive presentation}

In order to describe the sample, means and standard deviation (SD) were calculated for continuous data and frequency tables (n; \%) for categorical data. For the description of HRQoL, the frequency tables of self-reported problems across each of the five EQ-5D domains were presented. Summary index value of health status (EQ-5D-5 l) and the volume of PA at the workplace, in transport and in leisure time were described by means, SD, median, first and third quartile. The results on the volume of PA only relate to patients reporting any PA ( $>0$ min PA/week). Prevalence of physical inactivity was presented separately by frequency of patients reporting "no PA" in each life domain.

\section{Statistical tests}

Gender and age differences between participants in the study and non-participants were tested by Pearson Chi Square Test respectively Mann-Whitney- $U$ Test.

To explore the association between PA and HRQoL (question 1) and identify variables associated with HRQoL (question 2) multiple linear regression models were calculated. In the first model (question 1), solely the different domains of PA were included. In the second model (question 2), besides PA, the sociodemographic, work-related and indication-specific variables were included stepwise to get insight in what variables explained HRQoL best. The principal assumptions of linear regression were tested. In both regression models, participants with missing values in dependent or independent variables were excluded. For all statistical tests, significance level was set at $\mathrm{p}<0.05$. All analyses were run with IBM SPSS Statistics 22 .

\section{Results}

\section{Sample description}

Of 931 eligible patients, 412 gave informed consent and completed the questionnaire (participation rate $=44 \%$ ). Compared to non-participants, there was no significant difference regarding sex $(\mathrm{p}=0.18)$, but regarding age $(\mathrm{p}=0.04)$. In average, participants $($ mean $=50.4$ years; $\mathrm{SD}=8.1)$ were one year younger than non-participants (mean $=51.3$ years; $\mathrm{SD}=8.2 ; t$-test $\mathrm{p}=0.04$ ). Most frequent reasons cited for non-participation were privacy 
protection ( $\mathrm{n}=99 ; 19 \%)$ and language problems $(\mathrm{n}=91$; 18\%). 288 non-participants (55\%) did not state a reason.

The sample consisted of 286 men (69.4\%) and the mean age was $50.4( \pm 8.1)$ years. Sociodemographic and indicationspecific variables as well as work-related aspects of the sample are shown in Table 1.

\section{Descriptive results}

The prevalence of physical inactivity across different life areas is presented in Table 2. Vigorous leisure time shows highest prevalence of physical inactivity (71\%). Independent of intensity, $45 \%$ of the patients are not physically active at the workplace. In leisure time, 53\% show neither moderate nor vigorous PA. $19 \%(\mathrm{n}=79)$ do not show any PA of at least ten minutes duration in total PA, respectively in any life area (see Table 2).

PA data (min/week) of patients reporting PA are displayed in Table 3. In patients reporting PA, PA level at work is higher than in leisure time and PA for transportation. While median in moderate workplace PA is $840 \mathrm{~min} /$ week and in vigorous workplace PA even $1350 \mathrm{~min} /$ week, duration of transport (median $=270 \mathrm{~min} /$ week) and leisure time PA (vigorous: median = $150 \mathrm{~min} /$ week; moderate: median = $138 \mathrm{~min} /$ week) is considerably lower.

Table 4 shows frequency tables from the five domains of the EQ-5D instrument as well as mean index value of health status (dependent variable). Descriptive results from the five domains of the EQ-5D instrument showed most frequent severe $(25.5 \%)$ respectively extreme problems

\section{Table 1 Sample description}

\begin{tabular}{|c|c|}
\hline \multicolumn{2}{|l|}{ Whole population $n=412$} \\
\hline \multicolumn{2}{|l|}{ Sociodemographic variables } \\
\hline Age (years) (mean; SD) $(n=406)$ & $50.4(8.1)$ \\
\hline Gender: men $(n ; \%)(n=412)$ & $286(69.4 \%)$ \\
\hline BMI (mean; SD) ( $n=383)$ & $29.3(5.6)$ \\
\hline Overweight $(\mathrm{BMI} \geq 25-<30)(\mathrm{n} ; \%)$ & $166(43.3 \%)$ \\
\hline Obese $(\mathrm{BMI} \geq 30)(\mathrm{n} ; \%)$ & $144(37.6 \%)$ \\
\hline Living in partnership $(n ; \%)(n=400)$ & $308(77.0 \%)$ \\
\hline $\begin{array}{l}\text { Level of education (secondary modern school) } \\
(n ; \%)(n=399)\end{array}$ & $214(53.6 \%)$ \\
\hline \multicolumn{2}{|l|}{ Work-related aspects } \\
\hline $\begin{array}{l}\text { Sickness certificate before rehabilitation > six weeks } \\
(n ; \%)(n=396)\end{array}$ & $148(37.3 \%)$ \\
\hline Currently employed $(n ; \%)(n=395)$ & $318(80.5 \%)$ \\
\hline $\begin{array}{l}\text { Job satisfaction during the last four weeks }(0-7) \\
\text { (mean; SD) }(n=360)\end{array}$ & $3.2(2.2)$ \\
\hline Current workability $(0-10)($ mean; SD) $(n=387)$ & $4.5(2.5)$ \\
\hline \multicolumn{2}{|l|}{ Indication-specific variables } \\
\hline Duration of LBP > 12 months $(n ; \%)(n=400)$ & $343(85.8 \%)$ \\
\hline $\begin{array}{l}\text { Intensity of pain during the last four weeks } \\
\text { (min: } 1 \text {; max: 6) (mean; SD) }(n=378)\end{array}$ & $4.6(1.0)$ \\
\hline
\end{tabular}

Table 2 Frequency tables of physically inactive patients

\begin{tabular}{ll}
\hline Life domain and intensity of PA & $\begin{array}{l}\text { Number of patients } \\
\text { reporting no physical } \\
\text { activity }(\mathbf{n} ; \%)\end{array}$ \\
\hline No work PA & $185(45 \%)$ \\
No vigorous work PA $(n=412)$ & $251(61 \%)$ \\
No moderate work PA $(n=412)$ & $255(62 \%)$ \\
No transport PA $(n=412)$ & $238(58 \%)$ \\
No leisure time PA & $218(53 \%)$ \\
$\quad$ No vigorous leisure time PA $(n=412)$ & $291(71 \%)$ \\
No moderate leisure time PA $(n=412)$ & $278(68 \%)$ \\
No PA in all domains & $79(19 \%)$ \\
\hline
\end{tabular}

(8.9\%) in pain and discomfort, followed by daily activities (severe: 20.8\%; extreme: 2.2). Furthermore, severe problems in mobility are answered by $11.2 \%$. Majority of the patients reported no problems in self-care (57.3\%). The mean index value of health status (HRQoL) was $0.65( \pm 0.22)$.

For calculation of regression models, independent variables were classified as described in statistical analysis. Table 5 shows frequency tables of PA classes.

In the first step, model 1 , solely including dimensions of PA, was calculated (Table 6). There was a significant negative association of "moderate and vigorous workplace PA" and HRQoL ( $\beta=-0.064 ; \mathrm{p}=0.04)$. Patients reporting "moderate and vigorous workplace PA" were more likely to report lower HRQoL compared to patients reporting "no workplace PA". Furthermore, patients achieving WHO recommendations in leisure time ( $\geq 600$ MET-min/ week) showed a significantly higher HRQoL compared to patients reporting "no leisure time PA" $(\beta=0.068$; $\mathrm{p}=0.01)$. Overall, PA explained $3 \%$ of the variance of HRQoL $\left(\mathrm{R}^{2}=.033\right)$.

In model 2 (see Table 7) only two independent variables were statistically significant: The higher the current work ability compared to highest work ability ever, the higher was HRQoL ( $\beta=0.030 ; p<0.01)$. Furthermore, intensity of pain during the last four weeks was negatively associated with HRQoL, meaning that higher intensity of pain goes in line with lower HRQoL $(\beta=-0.104 ; \mathrm{p}<0.01)$. These two variables explained $35 \%$ of the variation in HRQoL $\left(R^{2}=0.350\right)$. In this regression model, no domain of PA showed a significant association.

\section{Discussion}

Main finding of the present study was that "moderate and vigorous workplace PA" showed a negative association with HRQoL while patients achieving WHO recommendations in leisure time showed a significantly higher HRQoL compared to patients reporting "no leisure time PA". Hence, solely the variables "current work ability" and "intensity of pain" contributed significantly to explain variance in HRQoL. 
Table 3 Domain specific physical activity of patients reporting PA

\begin{tabular}{|c|c|c|c|c|c|}
\hline Whole population $n=412$ & Mean & SD & Min; Max & Median & 25\%-; 75\%-percentile \\
\hline Vigorous work PA (min/week) $(n=161)$ & 1303 & 812 & $20 ; 2400$ & 1350 & $495 ; 2100$ \\
\hline Moderate work PA (min/week) $(n=157)$ & 1007 & 787 & $60 ; 2400$ & 840 & $360 ; 1500$ \\
\hline Transport PA (min/week) $(n=174)$ & 447 & 561 & $20 ; 3360$ & 270 & $120 ; 540$ \\
\hline Vigorous leisure time PA (min/week) $(n=121)$ & 242 & 250 & $20 ; 1200$ & 150 & $90 ; 300$ \\
\hline Moderate leisure time PA (min/week) $(n=134)$ & 244 & 346 & $20 ; 3360$ & 138 & $90 ; 270$ \\
\hline
\end{tabular}

First, the descriptive data of PA are discussed from an application-oriented point of view in order to identify whether lack of PA is a lifestyle factor to be targeted in this sample. The prevalence of persons achieving WHO recommendations corresponded to the results of representative surveys in Germany. There, different surveys showed a prevalence from $20.5 \%$ [32] to 54\% [33] what compares favorably with the results in the present study. The discussion, whether persons with CLBP show lower levels of PA is controversial. According to Lin et al. [34], chronic LBP patients with high levels of disability are likely to have low levels of PA. Several other studies showed that the mean activity of patients with chronic LBP does not differ from healthy individuals [35-37].

The present evaluation focused on the evaluation of $\mathrm{PA}$, as an important lifestyle factor, and its association to HRQoL. By investigating the associations of PA and HRQoL in LBP patients, especially the different types of PA should be taken into account. Regarding the domain specific minutes per week reported in the present study, the high values of workplace PA compared to leisure time PA were eye-catching. Scientific literature shows, that the differentiation of workplace and leisure time PA as well as intensity of PA is relevant in the context of assessing potential health-enhancing effects of PA in LBP. Our regression on the associations of PA and HRQoL (model) supported the assumption of opposed effects of leisure time PA and workplace PA: While "moderate and vigorous workplace PA" showed a negative association $(\beta=-0.064$; $\mathrm{p}=0.04$ ), leisure time PA “ $\geq 600 \mathrm{MET}$-min/week" showed a positive association $(\beta=0.068 ; p=0.01)$ to HRQoL. Independently of HRQoL, Jacob et al. showed that strenuous PA at work might lead to a significantly higher risk of back pain [38]. Junqueira and colleagues [39] showed higher prevalence of LBP associated with heavy work while moderate activities such as jogging seemed to be beneficial. Furthermore, there is evidence that the exposure to awkward positions is a risk factor for LBP. This is an aspect that was not measured in the present study and therefore needs to be considered in further investigations. Also Schneider and Schiltenwolf [40] found that LBP prevalence in occupations associated with high intensity and high volume PA at work was higher-than the average. Moreover, they show that professional groups associated with light PA, e.g. senior management, showed a lower prevalence [40]. Study results concerning leisure time PA, sports, physical exercise and risk of LBP are inconsistent: intensive activities are considered a risk factor for LBP, whereas moderate PA is, on the contrary, considered beneficial to health [41].

However, the findings showed no significant association of PA and HRQoL if further variables were considered to explain influences on HRQoL. The results contradict other studies, stating a relationship between level of PA and quality of life in LBP patients [42] as well as in general population $[10,43]$. Only two of the 14 variables included significantly contributed to explain the variance of HRQoL. As expected, high intensity of pain was related to low HRQoL ( $\beta=-0.104 ; \mathrm{p}<0.01$ ) what emphasizes the importance of pain management in CLBP patients. The association of current work ability $(\beta=0.030 ; \mathrm{p}<0.01)$ added weight to the assumption that especially workplace plays a crucial role regarding HRQoL. This is in line with results from Sörensen et al. [44] that suggest that the promotion of work ability may have beneficial effects on the quality of life. In consequence, rehabilitation practitioners and future

Table 4 Health Related Quality of Life

\begin{tabular}{|c|c|c|c|c|c|}
\hline Whole population $n=412$ & $\begin{array}{l}\text { No problems } \\
\mathrm{n}(\%)\end{array}$ & $\begin{array}{l}\text { Slight problems } \\
\text { n (\%) }\end{array}$ & $\begin{array}{l}\text { Moderate problems } \\
\mathrm{n}(\%)\end{array}$ & $\begin{array}{l}\text { Severe problems } \\
\mathrm{n}(\%)\end{array}$ & $\begin{array}{l}\text { Extreme problems } \\
\mathrm{n}(\%)\end{array}$ \\
\hline Mobility $(n=366)$ & $81(22.1 \%)$ & $97(26.5 \%)$ & $145(39.6 \%)$ & $41(11.2 \%)$ & $2(0.5 \%)$ \\
\hline Self-care $(n=372)$ & $213(57.3 \%)$ & $91(24.5 \%)$ & $63(16.9 \%)$ & $4(1.1 \%)$ & $1(0.3 \%)$ \\
\hline Daily activities $(n=371)$ & $34(9.2 \%)$ & $105(28.3 \%)$ & 147 (39.6\%) & $77(20.8 \%)$ & $8(2.2 \%)$ \\
\hline Pain and discomfort $(n=361)$ & $9(2.5 \%)$ & $55(15.2 \%)$ & $173(47.9 \%)$ & $92(25.5 \%)$ & $32(8.9 \%)$ \\
\hline \multirow[t]{2}{*}{ Anxiety or depression $(n=351)$} & $118(33.1 \%)$ & $108(30.3 \%)$ & $90(25.2 \%)$ & $29(8.1 \%)$ & $12(3.4 \%)$ \\
\hline & Mean & SD & Min; Max & Median & 25\%; 75\%-percentile \\
\hline Index value of health status $(0-1)(n=319)$ & 0.65 & 0.22 & $-0.11 ; 1.00$ & 0.72 & $0.49 ; 0.81$ \\
\hline
\end{tabular}


Table 5 PA classes (independent variables in the regression models)

\begin{tabular}{ll}
\hline & N (\%) \\
\hline Workplace PA $(n=412)$ & $185(44.9 \%)$ \\
"No workplace PA" & $136(33.0 \%)$ \\
"Moderate or vigorous workplace PA" & $91(22.1 \%)$ \\
"Moderate and vigorous workplace PA" & \\
"No transport PA" & $238(57.8 \%)$ \\
"Transport PA" & $174(42.2 \%)$ \\
Leisure time PA $(n=412)$ & \\
"No leisure time PA" & $218(52.9 \%)$ \\
"Leisure time PA < 600 MET-Min/week" & $55(13.3 \%)$ \\
"Leisure time PA $\geq 600$ MET-Min/week" & $139(33.7 \%)$ \\
\hline
\end{tabular}

research should focus on work-related aspects and its associations to HRQoL and in this context emphasize employment and vocational orientation in medical rehabilitation.

This research investigation has several strengths and limitations. As inclusion criteria were defined very broad, all patients prescribed inpatient rehabilitation because of LBP were included in the study. Due to logistic restrictions, specific problems related to LBP (e.g., leg pain; acute pain) could not be obtained. Also the participation rate of $44 \%$ and the monocentric study design are a limitation as they may cause a selection bias. Furthermore, as the present evaluation was performed in the context of an intervention study on promoting health-enhancing PA, primarily motivated patients may have responded. Due to missing values in independent variables, the regression models could only be fitted on subpopulations and therefore a further selection bias cannot be excluded. In consequence, implications for population mean of LBP patients have to be concluded very carefully. A second limitation is that the cross-sectional data cannot elucidate a possible causality of the associations. Thirdly, the self-reported operationalization of PA may induce a reporting bias due to overestimation [45]. To minimize this potential bias, a conservative plausibility data check was performed as described in the chapter methods. Hence, the decision about plausibility was only made on the basis of interdisciplinary discussions between practitioners and researchers and therefore no reference on cut-off values can be provided.

Apart from that, this study includes a number of important strengths. One such strength is the domain specific measurement of PA. By examining PA in different life areas and evaluating its domain specific associations to HRQoL, a gainful contribution assessing health-enhancing effects of PA in LBP is made. Furthermore, the comprehensive data collection enabled to capture often overlooked information such as work-related aspects. Another strength of the present study certainly is its concentration on HRQoL as an highly important outcome in rehabilitation and health services research. Whereas several studies and reviews on the relationship of PA and LBP are available, there is a lack of studies evaluating the association of PA and HRQoL in LBP patients. The present study therefore encounters the importance of the construct of HRQoL as a superior aim in rehabilitation and heath care service, as emphasized in German treaties on social law and utility analysis [8].

\section{Conclusion}

Leading patients to an active lifestyle is a superior aim of exercise therapy in rehabilitation $[19,46]$. Thereby, greater weight should be given to the life domain in which PA is conducted and especially leisure time PA should be promoted as it was associated with higher HRQoL. However, interventions on the promotion of health-enhancing PA should consider volume and intensity of workplace PA (e.g., consulting on how to reduce health-related PA load in patients with high workplace PA) and psycho-social aspects.

In the context of HRQoL it must be assumed that the relevance of PA is overestimated. However, as HRQoL is of utmost importance in rehabilitation and health care research, further research should be performed on the prognostic influence of PA and other relevant predictors on HRQoL in longitudinal studies. Thereby, particular attention should be paid to the patients' work-related aspects.

Table 6 Model 1 - Association of PA and Health Related Quality of Life

\begin{tabular}{|c|c|c|c|c|}
\hline $\mathrm{N}=319$ & Beta & SE $(\beta)$ & $95 \%-\mathrm{Cl}$ & Sig. \\
\hline \multicolumn{5}{|l|}{ Workplace PA } \\
\hline "Either moderate or vigorous workplace PA" vs. "no workplace PA" & -0.032 & 0.029 & $-0.089 ; 0.025$ & 0.27 \\
\hline "Moderate and vigorous workplace PA" vs. "no workplace PA" & -0.064 & 0.032 & $-0.126 ;-0.002$ & $0.04^{*}$ \\
\hline \multicolumn{5}{|l|}{ Transport PA } \\
\hline "Yes" vs. "no" & 0.002 & 0.025 & $-0.047 ; 0.052$ & 0.92 \\
\hline \multicolumn{5}{|l|}{ Leisure time PA } \\
\hline "<600 MET-min/week" vs. "no leisure time PA" & 0.068 & 0.039 & $-0.008 ; 0.144$ & 0.08 \\
\hline " $\geq 600$ MET-min/week" vs. "no leisure time PA" & 0.068 & 0.028 & $0.014 ; 0.123$ & $0.01^{*}$ \\
\hline
\end{tabular}

Dependent variable: summary health index (EQ-5D); $\mathrm{R}^{2}=.033 ;{ }^{*} p<0.05$; overall $\mathrm{p}=0.06$. 
Table 7 Model 2 - variables associated with Health Related Quality of Life

\begin{tabular}{|c|c|c|c|c|}
\hline $\mathrm{N}=\mathbf{2 6 7}$ & Beta & SE & $95 \%-\mathrm{Cl}$ & Sig. \\
\hline Intensity of pain during the last four weeks (min: 1 ; max: 6 ) & -0.104 & 0.013 & $-0.130 ;-0.078$ & $<0.01^{*}$ \\
\hline Current work ability (min: $0 ;$ max: 10 ) & 0.030 & 0.005 & $0.020 ; 0.040$ & $<0.01^{*}$ \\
\hline
\end{tabular}

Dependent variable: summary health index (EQ-5D); $R^{2}=0.350 ;{ }^{*}<0.05$; overall $p<0.01$.

Excluded variables: BMI, current employment status, sick certificate before rehabilitation, duration of LBP, workplace PA, leisure time PA, transport PA, age, gender, partnership, level of education.

\section{Endnote}

${ }^{\text {a }}$ The metabolic equivalent (MET) is a physiological measure expressing the expended energy of physical activities. MET is defined as the ratio of the rate of energy consumption during a specific physical activity to a reference metabolic rate. Vigorous intensity corresponded to $8 \mathrm{MET}$; moderate intensity corresponded to $4 \mathrm{MET}$.

\section{Competing interests}

The authors declare that they have no competing interests.

\section{Authors' contributions}

AS conceived the study and design, drafted the manuscript, performed the statistical analysis and edited the manuscript. LD contributed to editing of manuscript drafts. BH contributed to the study design, data analysis and interpretation. IF drafted all versions of the manuscript. All authors read and approved the final manuscript.

\section{Acknowledgements}

The present evaluation was conducted in the context of an intervention study on health enhancing PA promotion ("Bewegungscoaching"; German Clinical Trials Register (DRKS)-ID: DRKS00004878) funded by the German Statutory Pension Insurance Rhineland. The authors thank Aggertalklinik in Engelskirchen for cooperation.

\section{Author details}

${ }^{1}$ Institute of Health Promotion and Clinical Movement Science, German Sport University Cologne, Am Sportpark Muengersdorf 6, 50933 Cologne, Germany. ${ }^{2}$ mediStatistica, Lambertusweg 1b, 58809 Neuenrade, Germany.

Received: 20 August 2014 Accepted: 11 March 2015

Published online: 19 March 2015

\section{References}

1. U.S. Department of Health and Human Services. Physical activity and health: a report of the surgeon general. Atlanta, GA: Department of Health and Human Services, Centers for Disease Control and Prevention, National Center for Chronic Disease Prevention and Health Promotion; 1996.

2. Robert Koch-Institut. Körperliche Aktivität, vol. Volume 26. Berlin: Robert-Koch-Inst; 2005.

3. Lee I, Shiroma EJ, Lobelo F, Puska P, Blair SN, Katzmarzyk PT. Effect of physical inactivity on major non-communicable diseases worldwide: an analysis of burden of disease and life expectancy. Lancet. 2012;380:219-29.

4. World Health Organization (WHO). Global status report on noncommunicable diseases 2010. Geneva: World Health Organization; 2011.

5. Warburton DER, Nicol CW, Shannon SDB. Health benefits of physical activity: the evidence. CMAJ. 2006;174:801-9.

6. Vuori IM, Lavie CJ, Blair SN. Physical activity promotion in the health care system. Mayo Clin Proc. 2013;88:1446-61.

7. World Health Organization (WHO). Global recommendations on physical activity for health. Geneva: WHO Press; 2012.

8. Koller M, Neugebauer EAM, Augustin M, Büssing A, Farin E, Klinkhammer-Schalke M, et al. Die Erfassung von Lebensqualität in der Versorgungsforschung konzeptuelle, methodische und strukturelle Voraussetzungen. Gesundheitswesen. 2009;71:864-72

9. Torrance GW. Utility approach to measuring health-related quality of life. J Chronic Dis. 1987:40:593-603.
10. Bize R, Johnson JA, Plotnikoff RC. Physical activity level and health-related quality of life in the general adult population: a systematic review. Prev Med. 2007;45:401-15.

11. Breivik H, Collett B, Ventafridda V, Cohen R, Gallacher D. Survey of chronic pain in Europe: prevalence, impact on daily life, and treatment. Eur J Pain. 2006;10:287-333.

12. Savage SR, Kirsh KL, Passik SD. Challenges in using opioids to treat pain in persons with substance use disorders. Addict Sci Clin Pract. 2008;4:4-25.

13. Rejeski WJ, Brawley LR, Shumaker SA. Physical activity and health-related quality of life. Exerc Sport Sci Rev. 1996;24:71-108.

14. Schmidt CO, Kohlmann T. Was wissen wir über das Symptom Rückenschmerz? Epidemiologische Ergebnisse zu Prävalenz, Inzidenz, Verlauf, Risikofaktoren. Z Orthop Grenzgeb. 2005;143:292-8.

15. Freburger JK, Holmes GM, Agans RP, Jackman AM, Darter JD, Wallace AS, et al. The rising prevalence of chronic low back pain. Arch Intern Med. 2009;169:251-8.

16. Schmidt CO, Raspe H, Pfingsten M, Hasenbring M, Basler HD, Eich W, et al. Back pain in the German adult population: prevalence, severity, and sociodemographic correlates in a multiregional survey. Spine. 2007;32:2005-11.

17. Robert Koch-Institut. Rückenschmerzen, vol. 53. Berlin: Robert-Koch-Inst; 2012.

18. Burton AK, Balagué F, Cardon G, Eriksen HR, Henrotin Y, Lahad A, et al. How to prevent low back pain. Best Pract Res Clin Rheumatol. 2005;19:541-55.

19. van Tulder M, Becker A, Bekkering T, Breen A, del Real, Maria Teresa G, et al. Chapter 3. European quidelines for the management of acute nonspecific low back pain in primary care. Eur Spine J. 2006;15 Suppl 2:S169-91.

20. Koes BW, van Tulder MW, Ostelo R, Kim Burton A, Waddell G. Clinical guidelines for the management of low back pain in primary care: an international comparison. Spine. 2001;26:2504-13. discussion 2513-4.

21. Ferreira PH, Beckenkamp P, Maher CG, Hopper JL, Ferreira ML. Nature or nurture in low back pain? Results of a systematic review of studies based on twin samples. Eur J Pain. 2013;17:957-71.

22. Schaller A, Froboese I. Movement coaching: study protocol of a randomized controlled trial evaluating effects on physical activity and participation in low back pain patients. BMC Musculoskelet Disord. 2014;15:391.

23. Neumann PJ, Goldie SJ, Weinstein MC. Preference-based measures in economic evaluations in health care. Annu Rev Public Health. 2000;21:587-611.

24. EuroQol Group. EuroQol-a new facility for the measurement of health-related quality of life. Health Policy. 1990;16:199-208.

25. Oemar $M$, Janssen B. EQ-5D-5 L user quide- basic information on how to use the EQ-5D-5 L instrument. Rotterdam: EuroQol Group; 2013.

26. Armstrong T, Bull FC. Development of the world health organization global physical activity questionnaire (gpaq). J Public Health. 2006;14:66-70.

27. Bull FC, Maslin TS, Armstrong T. Global physical activity questionnaire (GPAQ): nine country reliability and validity study. J Phys Act Health. 2009;6:790-804.

28. World Health Organization (WHO). Global Physical Activity Questionnaire (GPAQ) analysis guide. Geneva: WHO Press; 2014.

29. World Health Organization. Obesity: Preventing and managing the global epidemic. Geneva: World Health Organization; 2000 [WHO Technical Report Series, vol. 894].

30. Tuomi K, Vanhala S, Nykyri E, Janhonen M. Organizational practices, work demands and the well-being of employees: a follow-up study in the metal industry and retail trade. Occup Med (Lond). 2004;54:115-21.

31. Bullinger M, Kirchberger I, Ware J. Der deutsche SF-36 Health Survey. Übersetzung und psychometrische Testung eines krankheitstibergreifenden Instruments zur Erfassung der gesundheitsbezogenen Lebensqualität. Z f Gesundheitswiss. 1995;3:21-36.

32. Krug S, Jordan S, Mensink GBM, Müters S, Finger J, Lampert T. Körperliche Aktivität. Ergebnisse der Studie zur Gesundheit Erwachsener in Deutschland 
(DEGS1). Bundesgesundheitsblatt Gesundheitsforschung Gesundheitsschutz. 2013;56:765-71.

33. Froböse I, Wallmann B. DKV-Report "Wie gesund lebt Deutschland?". Köln: Zentrum für Gesundheit; 2012.

34. Lin CC, McAuley JH, Macedo L, Barnett DC, Smeets RJ, Verbunt JA. Relationship between physical activity and disability in low back pain: a systematic review and meta-analysis. Pain. 2011;152:607-13.

35. Bousema EJ, Verbunt JA, Seelen, Henk AM, Vlaeyen, Johan WS, et al. Disuse and physical deconditioning in the first year after the onset of back pain. Pain. 2007;130:279-86.

36. van Weering MGH, Vollenbroek-Hutten MMR, Tönis TM, Hermens HJ. Daily physical activities in chronic lower back pain patients assessed with accelerometry. Eur J Pain. 2009:13:649-54.

37. Verbunt JA, Westerterp KR, van der Heijden GJ, Seelen HA, Vlaeyen JW, Knottnerus JA. Physical activity in daily life in patients with chronic low back pain. Arch Phys Med Rehabil. 2001;82:726-30.

38. Jacob T, Baras M, Zeev A, Epstein L. Physical activities and low back pain: a community-based study. Med Sci Sports Exerc. 2004;36:9-15.

39. Junqueira DRG, Ferreira ML, Refshauge K, Maher CG, Hopper JL, Hancock M, et al. Heritability and lifestyle factors in chronic low back pain: results of the Australian Twin Low Back Pain Study (The AUTBACK study). Eur J Pain. 2014;18:1410-8

40. Schneider S, Schiltenwolf M. Welche Berufe bergen ein erhöhtes Rückenschmerzrisiko?-Repräsentative Ergebnisse zur RückenschmerzPrävalenz unter bundesdeutschen Erwerbstätigen. Versicherungsmedizin. 2007:59:67-72

41. Heneweer H, Staes F, Aufdemkampe G, van Rijn M, Vanhees L. Physical activity and low back pain: a systematic review of recent literature. Eur Spine J. 2011;20:826-45.

42. Stevens SL, Caputo JL, Fuller DK, Morgan DW. Physical activity and quality of life in adults with spinal cord injury. J Spinal Cord Med. 2008;31:373-8.

43. Jurakić $D$, Pedišić $Z$, Greblo Z. Physical activity in different domains and health-related quality of life: a population-based study. Qual Life Res. 2010;19:1303-9.

44. Sörensen LE, Pekkonen MM, Männikkö KH, Louhevaara VA, Smolander J, Alén MJ. Associations between work ability, health-related quality of life, physical activity and fitness among middle-aged men. Appl Ergon. 2008;39:786-91.

45. Slootmaker SM, Schuit AJ, Chinapaw MJ, Seidell JC, van Mechelen W. Disagreement in physical activity assessed by accelerometer and self-report in subgroups of age, gender, education and weight status. Int J Behav Nutr Phys Act. 2009;6:17.

46. Sudeck G, Pfeifer K. Bewegung in der Rehabilitation - ICF-Bezug, Kompetenzorienzierung, Nachhaltigkeit. Public Health Forum. 2013; 21(2): doi:10.1016/j.phf.2013.03.013.

\section{Submit your next manuscript to BioMed Central and take full advantage of:}

- Convenient online submission

- Thorough peer review

- No space constraints or color figure charges

- Immediate publication on acceptance

- Inclusion in PubMed, CAS, Scopus and Google Scholar

- Research which is freely available for redistribution 